M+A Revista Electrónica de Medioambiente ISSN-e: 1886-3329

http://dx.doi.org/10.5209/MARE.57982

\title{
Responsabilidad ambiental en Chile. Análisis basado en la regulación comunitaria y española
}

\author{
María Jesús Pinochet Abalos ${ }^{1}$ \\ Recibido: 15 de septiembre del 2017/ Enviado a evaluar: 19 de septiembre del 2017/ Aceptado: 10 de noviembre del 2017
}

Resumen. La Ley No 19.300 de 1994, sobre Bases Generales del Medio Ambiente, entre otras cosas, integró al ordenamiento jurídico reglas que en su conjunto constituyen un régimen especial de responsabilidad ambiental con las reformas introducidas por la Ley $\mathrm{N}^{\mathrm{o}} 20.417$ de 2010 y la Ley $\mathrm{N}^{\mathrm{o}}$ 20.600 de 2012, que crean la nueva institucionalidad ambiental, se reconoce a los Tribunales Ambientales como organismos competentes para conocer las acciones de reparación por daño ambiental. En este contexto, se hace necesario realizar un examen de la regulación de responsabilidad ambiental para efectos de dilucidar si las referidas modificaciones han contribuido en el perfeccionamiento del sistema. El estudio se realiza con base a la Directiva 2004/35/CE sobre responsabilidad medioambiental en relación con la prevención y reparación de daños ambientales, y a la Ley 26/2007 de Responsabilidad Medioambiental

Palabras clave: Responsabilidad ambiental; daño ambiental; reparación del daño ambiental.

\section{[en] Environmental responsibility in Chile. Analysis based on community and Spanish regulations}

\begin{abstract}
The law N 19.300 of 1994, base on the Environment, among other things, integrated into the legal system rules that has been constituted a special regime of environmental responsibility. Then, with the reforms introduced by the Law $N^{\circ} 20.417$ of 2010 and the Law $N^{\circ} 20.600$ of 2012, which have created the new environmental institutionality, the Environmental Courts is recognized as a competent part to know the actions of reparation for environmental damage. In this context, it is necessary to carry out a review of the environmental liability regulation in order to clarify the modifications that have contributed to the improvement of the system. The study is based on 2004/35/ EC Directive on environmental liability in relation to the prevention and repair of environmental damages, with the Law $N^{\circ} 26 / 2007$ on Environmental Responsibility.
\end{abstract}

Keywords: Environmental responsibility; environmental damage; environmental damage repair.

1 Universidad Diego Portales (Chile)

jesuspinochet@gmail.com 


\title{
[fr] Responsabilité environnementale au Chili. Analyse basée sur la réglementation communautaire et espagnole
}

\begin{abstract}
Résumé. Loi ${ }^{\circ} 19.300$ de 1994, sur les bases générales de l'environnement, entre autres, intégrée dans les règles du système juridique qui constituent ensemble un régime spécial de responsabilité environnementale avec les réformes introduites par la loi $\mathrm{n}^{\circ} 20.417$ de 2010 et la loi ${ }^{\circ} 20.600$ de 2012 , qui créent la nouvelle institutionnalité environnementale, les tribunaux de l'environnement sont reconnus comme des organismes compétents pour connaître les actions de réparation pour les dommages environnementaux. Dans ce contexte, il est nécessaire de procéder à un examen du règlement sur la responsabilité environnementale afin de déterminer si les modifications susmentionnées ont contribué à l'amélioration du système. L'étude est réalisée sur la base de la directive 2004/35 / CE sur la responsabilité environnementale en matière de prévention et de réparation des dommages environnementaux, et de la loi 26/2007 sur la responsabilité environnementale
\end{abstract}

Mots clés: Responsabilité environnementale; les dommages environnementaux; réparation de dommages environnementaux.

Cómo citar. Pinochet Abalos, M. J. (2017): Los espacios verdes en la ciudad sostenible. $M+A$ Revista Electrónica de Medioambiente, 18(2), 137-161.

Sumario. 1. Introducción. 2. Elementos de la responsabilidad ambiental. 2.1. Daño ambiental. 2.2. Los sujetos responsables. 2.3. Forma de imputación. 2.4. Relación de causalidad. 2.5. Legitimación activa. 2.6. Prescripción. 2.7. Reparación del daño ambiental. 3. Conclusiones. 4. Bibliografía.

\section{Introducción}

La civilización moderna altamente industrializada, ha contribuido de manera considerable en el deterioro progresivo del medio ambiente. Esta situación tiene efectos evidentes que también están impactando directamente en nuestra calidad de vida: escasez de recursos naturales, fenómenos climáticos extremos, sequías entre otros.

En este contexto, la protección del medio ambiente se presenta como un imperativo, y los Estados son cada vez más consientes al respecto y reconocen que en la actualidad, esta materia constituye uno de los principales desafíos. Este reto además supone establecer mecanismos orientados a repararlo en caso que éste haya sido dañado, y es ahí donde la responsabilidad por daño ambiental cobra gran importancia. Así, la creciente conciencia social sobre la importancia del medio ambiente y la necesidad de protegerlo ha derivado en una evolución progresiva de los ordenamientos jurídicos en esta materia. Se ha comprendido la importancia de establecer mecanismos jurídicos más eficaces para lograr este objetivo y particularmente, sobre la relevancia de consagrar normas especiales para reparar el 
daño ambiental, debido fundamentalmente a la particularidad de este tipo de daños ${ }^{2} \mathrm{y}$ a la insuficiencia de los regímenes tradicionales de responsabilidad extracontractual para abordarlos. Así, las regulaciones específicas sobre responsabilidad ambiental, establecen ciertos elementos particulares que en mayor o menor medida, se presentan como mecanismos para contribuir a superar las dificultades asociadas al daño ambiental.

En Chile, con la entrada en vigencia de la Ley No 19.300 de 1994, sobre Bases Generales del Medio Ambiente [LGBMA], entre otras cosas, se integró al ordenamiento jurídico reglas que en su conjunto constituyen un régimen especial de responsabilidad ambiental. Posteriormente, con las reformas introducidas por la Ley $\mathrm{N}^{\mathrm{o}} 20.417$ de 2010, que crea el Ministerio, el Servicio de Evaluación Ambiental y la Superintendencia del Medio Ambiente y la Ley $N^{0} 20.600$ de 2012, que crea los Tribunales Ambientales [LTA], el régimen de responsabilidad ambiental se tuvo que adecuar al nuevo marco institucional. En este contexto, encontrándose consolidada la nueva institucionalidad ambiental, es importante hacer un examen del sistema de responsabilidad por daño ambiental de la LGBMA, sobre todo considerando que desde la última reforma el conocimiento de estas causas son de competencia de los Tribunales Ambientales $[\mathrm{TA}]^{3}$, cuya composición es de carácter mixto y especializada ${ }^{4}$.

En efecto, este trabajo analiza los principales elementos que estructuran este sistema para determinar si el hecho que las demandas de reparación por daño ambiental estén sometidas al conocimiento de una judicatura especializada ha contribuido en su perfeccionamiento. La evaluación se realiza con base al sistema comunitario, aprobado por la Directiva 2004/35/CE del Parlamento Europeo y del Consejo, sobre responsabilidad medioambiental en relación con la prevención y reparación de daños ambientales, [DRMA], y también al régimen español establecido

\footnotetext{
${ }^{2}$ Así por ejemplo, un tipo de daño ambiental son los daños históricos, que son aquellos causados en un momento determinado pero que se manifiestan mucho tiempo después de producido el suceso que los ocasionó, por tanto, el problema que presentan este tipo de daños es la fijación del plazo de prescripción de la responsabilidad. También son frecuentes los daños difusos, cuya causa u origen no es posible de determinar del todo.

${ }^{3}$ El Art. 5 de la LTA establece que son tres los tribunales, cuya competencia relativa o territorial se define por macrozonas: El Primer Tribunal Ambiental (norte); Segundo Tribunal Ambiental (centro) y; el Tercer Tribunal Ambiental (sur). En relación al Primer Tribunal Ambiental, cabe hacer presente que su instalación y funcionamiento estaría fijada recién para septiembre del año 2017. Mientras esto no se instale el Tribunal, la competencia sobre las regiones de la macrozona norte le corresponde al Segundo Tribunal Ambiental con sede en Santiago. Con la instalación del Primer Tribunal Ambiental, se consolida la institucionalidad ambiental, conformada además por el Servicio de Evaluación Ambiental, la Superintendencia del Medio Ambiente y el Ministerio del Medio Ambiente.

${ }^{4}$ Cada Tribunal Ambiental estará integrado por tres ministros. Dos de ellos deberán tener título de abogado especializada en materias de Derecho Administrativo o Ambiental, y el tercero será un licenciado en Ciencias con especialización en materias medioambientales [Art.2 LTA].
} 
en la Ley 26/2007, de Responsabilidad Medioambiental [LRMA], que traspone la DRMA, en atención a las particularidades que presentan estos regímenes y con la finalidad de identificar las lecciones que estas regulaciones pudiesen aportar. Por último, también se pretende dar cuenta de los principales elementos que le otorgan el carácter especial a los sistemas especiales de responsabilidad ambiental y que lo diferencian de los sistemas tradicionales.

Este trabajo comienza analizando el alcance de los elementos configurativos de cada régimen de responsabilidad, identificando las principales diferencias, las particularidades y falencias que pudieran tener; y posteriormente se plantean observaciones respecto del análisis a modo de conclusión.

Con todo, desde ya cabe advertir que las principales diferencias entre los sistemas que se analizan son estructurales y se deben fundamentalmente a la naturaleza del procedimiento en que se determinan la responsabilidad ambiental: La Unión Europea y España regulan sistemas administrativo mientras que la legislación chilena contempla como régimen general uno de carácter judicial. ${ }^{5}$ Además, la DRMA y la LRMA, consideran una regulación dispone expresamente una doble finalidad prevenir y reparar el daño ambiental. La ley española también plantea por objeto la evitación del daño.

\section{Elementos de la responsabilidad ambiental}

\subsection{Daño ambiental}

El daño ambiental constituye el presupuesto elemental de la responsabilidad ambiental, solo si éste se produce surgirá la obligación de reparar los perjuicios ocasionados como en cualquier tipo de responsabilidad. ${ }^{6}$ Es importante examinar la

5 Cabe señalar mediante la Ley $\mathrm{N}^{\circ} 20.417$, se integra al ordenamiento jurídico ambiental mecanismo voluntario para obtener exclusivamente la reparación de daños ambientales en sede administrativa, y se materializa a través del plan de reparación ambiental. Este plan, según la regulación actual es una herramienta diseñada para complementar el sistema de fiscalización ambiental a cargo de la Superintendencia del Medio Ambiente [SMA], y constituye uno de los instrumentos de incentivos al cumplimiento de la regulación ambiental. Sin embargo es una vía de reparación bastante limitada ya que solo puede operar en el contexto del término de un procedimiento sancionatorio, únicamente cubre los daños ambientales ocasionados por la infracción de normativa ambiental y además, solo puede operar en caso que el infractor en dicho contexto presente voluntariamente una propuesta de plan de reparación ambiental. Además, desde la incorporación de este instrumento en el ordenamiento jurídico ambiental, hasta la fecha no ha sido utilizado por los infractores.

${ }^{6}$ Son varios los autores los que destacan el daño ambiental como presupuesto de la responsabilidad ambiental: ESTEVE PARDO JOSÉ (2008). "Ley de responsabilidad medioambiental. Comentario sistemático". Marcial Pons. Madrid. P. 33; BETANCOR RODRÍGUEZ A. (2014) "Derecho Ambiental". La Ley Grupo Wolters Kluwer. Madrid. P 1737 y ss.; GARCÍA AMEZ 
noción de daño ambiental que ofrece cada regulación ya que según la definición que se le otorgue, se delimita el ámbito de aplicación del sistema de responsabilidad ambiental. Para determinar el concepto de daño ambiental se tienen que considerar tres elementos:

\section{Daño:}

Los tres sistemas se refieren a la forma en que se debe producir el daño. La LGBMA establece expresiones sinónimas de daño o perjuicio toda pérdida, disminución, detrimento o menoscabo [Art. 2 letra e)]. Lo relevante es destacar que no importa la manera en que se manifieste el daño para que surja responsabilidad. ${ }^{7}$

Por otra parte, tanto la DRMA como la LRMA, señalan que el daño se manifiesta como un "cambio adverso mensurable de un recurso natural o el perjuicio mensurable a un servicio de recursos naturales, tanto si se producen directa como indirectamente". En efecto, el daño se debe presentar en un recurso natural determinados, como se verá- o en un servicio de recursos naturales ${ }^{8}$ y necesariamente debe suponer un perjuicio para los mismos.

\section{Que afecte al medio ambiente}

El legislador chileno no delimitó el concepto de medio ambiente para efectos de configurar la responsabilidad, por lo que hay que atenerse a la definición general que ofrece la LGBMA, según la cual, medio ambiente es el sistema global constituido por elementos naturales y artificiales de naturaleza física, química o biológica, socioculturales y sus interacciones, en permanente modificación por la acción humana o natural y que rige y condiciona la existencia y desarrollo de la vida en sus múltiples manifestaciones [Art. 2 letra 11)]. Por lo tanto, el concepto de daño ambiental tiene un carácter amplio y cualquier perjuicio ocasionado a los elementos que componen el medio ambiente puede ser estimado como tal, sean naturales o artificiales, de naturaleza física, química o biológica, socioculturales.

En relación a este aspecto, la DRMA ni la LRMA lo presentan como una tautología, ya que el daño ambiental no es el daño ocasionado al medio ambiente como sistema global o a todos los componentes que lo conforman, sino que aquel que afecta a las especies y hábitats naturales protegidos, el agua y el suelos [Art. 2.12

JAVIER. (2015) "Responsabilidad por daños al medio ambiente" Thomson Reuters Aranzadi. Pamplona P.91, entre otros.

7 BERMÚDEZ SOTO J. (2015) "Fundamentos del derecho ambiental". Ediciones Universidad de Valparaíso. Pontificia Universidad Católica de Valparaíso. $2^{\circ}$ Edición P.10

${ }^{8}$ Los servicios de recursos naturales se definen como "las funciones que desempeña un recurso natural en beneficio de otro recurso natural o del público" [Art. 2.13 DRMA y Art. 2.18 LRMA]. Además, los servicios de recursos naturales se suelen clasificar en tres: (i) servicios de provisión -agua dulce, recursos genéticos-; (ii) servicios de regulación -del clima, erosión, riesgos naturales, etc.- y; (iii) servicios culturales -de turismo, recreación, etc.-Véase LOZANO CUTANDA B. (2017) "Derecho ambiental administrativo", 10 "Edición, Madrid. P.283 
DRMA]. Además, cabe destacar que la LRMA en relación a la DRMA extiende su ámbito de aplicación debido a que incorpora a la ribera del mar y de las rías como objeto de protección.

En suma, resulta importante la amplitud con la que se establece el bien jurídico protegido ya que está relacionado con la posibilidad de exigir la responsabilidad en caso de ocasionarle un daño. En el sistema chileno cualquier afectación o perjuicio en el medio ambiente en general o en cualquiera de sus elementos podría configurar un daño ambiental. En cambio, según los sistemas de la DRMA y LRMA solo podría imputarse responsabilidad ambiental cuando se afecte determinados elementos ambientales, por lo tanto, habrían casos en que aún generándose daño ambiental respecto a ciertos componentes, no podría establecerse responsabilidad ambiental.

\section{Significancia o intensidad del daño}

No todo daño ambiental genera responsabilidad, el perjuicio tiene que tener cierta envergadura o intensidad. En otras palabras, el sentido de este requisito es excluir de la responsabilidad aquellos innumerables impactos ambientales de mínima trascendencia, que quedarían cubiertos de adoptarse un concepto puramente naturalístico del daño.

El sistema de responsabilidad de la LGBMA, en el Art. 2 letra e) establece expresamente que el daño ambiental debe ser significativo. Sin embargo, no establece criterios para su determinación. En este sentido, la doctrina ha señalado que debido a que la la ley no contiene parámetros que permitan una calibración objetiva de la significación de los daños infligidos al medio ambiente, esta determinación queda entregada en definitiva a lo que resuelvan al respecto los jueces del fondo, con el margen de subjetivismo y de imprevisibilidad que ello conlleva. ${ }^{10}$ Ante la omisión del legislador sobre lineamientos que determinen la significancia del daño ambiental, su alcance se ha definido en atención al desarrollo doctrinario y jurisprudencial, principalmente.

En este sentido, la doctrina con base a la experiencia comparada, ha señalado los siguientes criterios a considerar en la tarea de ponderar el daño: ${ }^{11}$ (i) si el daño afecta a la salud de las personas siempre debe considerarse significativo; (ii) cuando el daño no es razonablemente tolerable por un ciudadano medio, entonces debe estimarse como significativo; (iii) la naturaleza del lugar donde se produce el daño; (iv) forma de manifestarse el daño, su intensidad y duración y; (v) al ponderar la significancia

${ }^{9}$ RUDA GONZÁLEZ A. (2008) "El daño ecológico puro. La Responsabilidad civil por el deterioro del Medio Ambiente, con especial atención a la Ley 26/2007, de 23 de octubre, de Responsabilidad Medioambiental." Thomson Aranzadi. Navarra. P.101

${ }^{10}$ VALENZUELA R. (2010). "El Derecho Ambiental, presente y pasado". Editorial Jurídica de Chile. P. 318

${ }^{11}$ BERMÚdEZ SOTO J. (2015) "Fundamentos del derecho (...)" [Ob. cit. No 22]. P.401-404 
del daño no deben considerarse las desventajas de otro tipo, principalmente económicas.

Por otra parte, a través de la jurisprudencia también se han definido y asentado criterios para definir la entidad del daño ambiental. La Corte Suprema ha establecido que no solo se debe considerar la extensión materia del daño, sino que también la fragilidad del ecosistema afectado. ${ }^{12}$ El TA, citando a la Corte Suprema, ha señalado criterios cualitativos -como la vulnerabilidad del componente ambiental- y cuantitativos - duración y magnitud del daño, cantidad de recursos afectados-, y profundizado en su alcance. ${ }^{13}$

Por su parte, la DRMA y la LRMA, para evaluar su entidad o significancia incorporan una serie de parámetros. Un primer aspecto, que se exige es tener en cuenta el estado básico del recurso natural o servicio de recurso natural afectado, que es aquel que aquellos tenían antes de producirse el daño. También, se señalan diferentes elementos que se deben considerar según el componente ambiental de que se trate, y en sus respectivos Anexos I, se establecen elementos que deben seguirse para ponderar la significancia del daño. Asimismo, el Reglamento de la LRMA ${ }^{14}$ [RLRMA] desarrolla con mayor detalles esta materia estableciendo una metodología primero para determinar el daño, y luego para evaluar la significancia del daño. Por tanto, estos sistemas regularía una tipología de daños ambientales. ${ }^{15}$

Atendido por una parte los parámetros que establece la DRMA, la LRMA y su reglamento, y por otra, los criterios doctrinales y jurisprudenciales, es posible identificar los siguientes elementos y consideraciones -casi todas comunes- para ponderar la significancia del el daño:

- Evaluar del componente ambienta afectado en atención al estado en que se encontraba justo anterior de producirse el daño y también al agente contaminante estado básico-.

- Criterios cuantitativos: (i) temporalidad del daño -implica considerar la duración del daño, si es intermitente y si los perjuicios que ocasiona son reversibles-; (ii) intensidad o grado de severidad del daño y; (iii) cantidad de componentes ambientales afectados

- Criterios cualitativos. No es suficiente considerar criterios cuantitativos, además se deben evaluar las características propias del componente afectado, teniendo en cuenta, por ejemplo: Su vulnerabilidad o fragilidad; tipo de zona afectada por el daño, esto es si se trata o no de una zona protegida, por ejemplo; posibilidad de recuperación propia del componente o servicio natural.

\footnotetext{
${ }_{12}^{12}$ Sentencia de la Corte Suprema, causa Rol: 5826-2009, Considerando N ${ }^{\circ} 7$

13 Por ejemplo véase sentencia de causa D-14-2014, considerandos $\mathrm{N}^{\mathrm{0}} 30$ a 32, y sentencia causa Rol 15- 2015, Considerandos $\mathrm{N}^{\circ} 12^{\circ}$ y 13, ambas del Segundo Tribunal Ambiental.

${ }_{14}$ Real Decreto 2090/2008, de 22 de diciembre, establece el Reglamento de desarrollo parcial de la Ley 26/2007

${ }^{15}$ ESTEVE PARDO JOSÉ (2008). "Ley de responsabilidad medioambiental. Comentario sistemático". Marcial Pons. Madrid. P. 28
} 
- Si el daño afecta a la salud humana deberá considerarse significativo.

Sumado a lo anterior, cabe referirse a la exigencia de la efectividad de ocurrencia del daño ambiental para efectos de imputar responsabilidad. Al respecto, tanto la DRMA como la LRMA consideran un régimen de responsabilidad que no solo se activa cuando el daño se ha producido, que es el supuesto común en los sistemas de responsabilidad, sino también cuando exista una amenaza inminente de que tales daños ocurran, que significa una probabilidad suficiente de que se produzcan daños medioambientales en un futuro próximo [Art. 2.9 LRMA]. Este supuesto se encuadra en el concepto de riesgo de carácter agudo, y sitúa la probabilidad como eje para su determinación. ${ }^{16}$ Sobre este punto, importa destacar que, aunque la LGBMA en el título III en que se regula la responsabilidad por daño ambiental no establece que por el riesgo de daño ambiental se puede imputar responsabilidad. Sin embargo, el TA, realizando una interpretación integral y finalista de la LGBMA y de la LOSMA, con base a todas las disposiciones que se refieren al riesgo de daño, citando jurisprudencia de la Corte Suprema, y haciendo referencia a doctrina comparada, a la legislación de la UE, particularmente a la DRMA, establece que el concepto de riesgo se debe entenderse integrado en el concepto de daño ambiental. ${ }^{17}$ La dimensión preventiva y de evitación del daño ambiental también se confirma por el establecimiento de medidas cautelares innovativas. ${ }^{18}$

\footnotetext{
16 Ídem P. 37

${ }^{17}$ Sentencia del Tribunal Ambiental de Santiago, causa Rol D-06-2013, Considerandos No 37 a 41 .

${ }^{18}$ Son aquellas medidas cautelares que pueden ser decretadas por el Tribunal, en cualquier estado del proceso o antes de su inicio y por el plazo que estime conveniente, a petición de parte o de oficio y que buscan modificar el estado de hecho o de derecho existente al tiempo de la solicitud de la medida y solo podrán decretarse ante la inminencia de un perjuicio irreparable. [Art. 24 LTA]

Por ejemplo, el Segundo Tribunal Ambiental, en causa Rol D-15-2015, a solicitud de la parte demandante -Municipalidad de Maipú-, decretó una medida cautelar innovativa consistente en el retiro de toda la maquinaria y vehículos de trabajo, y el desalojo de todo el personal que labora en la faena, excepto el que cumpla funciones de vigilancia, por el plazo máximo de 15 días hábiles, al considerar Tribunal que existen antecedentes suficientes que hacen plausible la inminencia de un perjuicio irreparable, y que el retraso o la demora en otorgar lo solicitado puede aumentar el riesgo afectación significativa del medio ambiente. [Resolución de fecha 10-03-2015].
} 


\subsection{Los sujetos responsables}

La LGBMA, no contempla una referencia expresa a los sujetos pasivos, solo se limita a establecer que el sistema se aplica a "todo el que" cause daño ambiental [Art. 51]. ${ }^{19}$ Lo anterior, según BERMÚDEZ debe entenderse en el sentido de que pueden resultar responsables por este régimen todos los sujetos privados, sean personas naturales o jurídicas, y también en principio, a sujetos públicos. En este orden de ideas, como señala el citado autor, la referida expresión "es una manifestación del principio general de que todo aquel que causa está obligado a repararlo". ${ }^{20}$

Por su parte, el ámbito de imputabilidad de la DRMA y la LRMA $^{21}$, es más restringido ya que solo puede aplicarse respecto a los operadores, que realicen determinadas actividades económicas -dependiendo si las actividades se encuentran o no en el respectivo Anexo III, se definirá si se aplica el estatuto subjetivo u objetivo de responsabilidad-. En consecuencia, para efectos que opere el régimen de responsabilidad ambiental, no basta la concurrencia del daño ambiental o de una amenaza inminente de tales -limitado además respecto a determinados elementos naturales-, sino que además es necesario que haya sido ocasionado por operadores al desarrollar determinadas actividades. Sin embargo, cabe precisar que las hipótesis de sujetos responsables no es del todo limitada, ya que por operador no solo debe considerarse al titular o propietario de una empresa o actividad, sino que también puede ser calificado como tal cualquier otro sujeto que desarrolle dicho emprendimiento, con base a cualquier otro título. Por tanto, la expresión "operador" resulta ser acertada. ${ }^{22}$

Además resulta relevante destacar que la LRMA contempla de forma expresa una serie de figuras jurídicas con la finalidad de garantizar el cumplimiento de las obligaciones que establece la Ley, tales como la responsabilidad subsidiaria y solidaria y también regula supuestos como la responsabilidad de los grupos de sociedades, pluralidad de responsables y la muerte o extinción de los responsables, con la misma finalidad. Por su parte, considerando el Art. 51 de la LGBMA, que

${ }^{19}$ El Art. 51 LGBMA dispone: "Todo el que culposa o dolosamente cause daño ambiental responderá del mismo en conformidad a la presente ley (...)".

20 BERMÚDEZ SOTO J. (2015) "Fundamentos del derecho ambiental". Ediciones Universidad de Valparaíso. Pontificia Universidad Católica de Valparaíso. $2^{\circ}$ Edición. P.395

${ }^{21}$ Conforme la LRMA operador es "cualquier persona física o jurídica, pública o privada, que desempeñe una actividad económica o profesional o que, en virtud de cualquier título, controle dicha actividad o tenga un poder económico determinante sobre su funcionamiento técnico. (...)" [Art. 2.10]. A su vez, se define a la actividad económica o profesional como "toda aquélla realizada con ocasión de una actividad de índole económica, un negocio o una empresa, con independencia de su carácter público o privado y de que tenga o no fines lucrativos" [Art. 2.11].

${ }^{22}$ DOPAZO FRAGUIO, P., (2005) "El sistema jurídico de responsabilidad medioambiental: Análisis de riesgos y compliance legal”, en Revista Aranzadi de Derecho Ambiental, número en Homenaje al Profesor D. Ramón Martín Mateo, 2015. Editorial Thomson- Aranzadi. P. 4. 
reconoce la aplicación supletoria de las disposiciones del título XXXV del Libro IV del Código Civil -de los delitos y cuasidelitos- podrían aplicarse reglas de responsabilidad solidaria. ${ }^{23}$

\subsection{Forma de imputación}

Este elemento de la responsabilidad, supone definir si para que haya responsabilidad basta con acreditar el daño y nexo causal con la conducta del agente del daño o en cambio, además se requiere acreditar concurrencia de culpa o dolo. Este es uno de los aspectos más difíciles de definir en un régimen de responsabilidad. Respecto a esta materia GARCÍA señala que el requisito de culpabilidad es una opción que puede o no tomar el legislador, pero considerando como limitación la prohibición de la interdicción de la arbitrariedad y los derechos a la presunción de inocencia y a la tutela efectiva. ${ }^{24}$

El régimen de responsabilidad ambiental de la LGBMA, se apega a la regla general y aplica el estatuto subjetivo [Art. 3 y Art. 51 inc. 1]. No obstante, prevalecerán las leyes especiales de responsabilidad por daño ambiental por sobre las que la LGBMA establece. ${ }^{25}$ Sin embargo, la regulación reconoce algunos mecanismos que permiten atenuar el requisito subjetivo de la responsabilidad, que consiste en una presunción de culpabilidad establecida en el Art. 52 de la LGBMA ${ }^{26}$. Esta norma es uno de los aspectos que le otorga el carácter especial al sistema, y que lo diferencian

${ }^{23}$ Art. 2317 del Código Civil: "Si un delito o cuasidelito ha sido cometido por dos o más personas, cada una de ellas será solidariamente responsable de todo perjuicio procedente del mismo delito o cuasidelito, salvas las excepciones de los artículos 2323 y 2328. Todo fraude o dolo cometido por dos o más personas produce la acción solidaria del precedente inciso".

24 GARCÍA AMEZ JAVIER. (2015) "Responsabilidad por daños al medio ambiente" Thomson Reuters Aranzadi. Pamplona. P.235-236.

${ }^{25}$ Entre las normas especiales por responsabilidad ambiental, se encuentran la Ley de seguridad nuclear, que reconoce un sistema objetivo de responsabilidad [Art. 49]; el D.L. 3.557/1981, Ley de Protección agrícola, que establece responsabilidad objetiva por los daños ocasionados a terceros por el uso de plaguicidas [Art.36]; el D.L. 2.222/1978, Ley de navegación que dispone un sistema de responsabilidad objetiva por contaminación acuática [Art. 144]; y la recientemente vigente Ley $\mathrm{N}^{\mathrm{O}}$ 20.920/ 2016, que establece marco para la gestión de residuos, la responsabilidad extendida del productor y fomento al reciclaje, dispone de responsabilidad de carácter objetivo respecto de los daños ocasionados por el manejo de residuos peligrosos, sin perjuicio de las correspondientes sanciones administrativas que establece la misma Ley [Art. 43].

${ }^{26}$ Art. 52 LGBMA: "se presume legalmente la responsabilidad del autor del daño ambiental, si existe infracción a las normas de calidad ambiental, a las normas de emisiones, a los planes de prevención o de descontaminación, a las regulaciones especiales para los casos de emergencia ambiental o a las normas sobre protección, preservación o conservación ambientales, establecidas en la presente ley o en otras disposiciones legales o reglamentarias. (...)". 
del régimen tradicional de responsabilidad extracontractual. ${ }^{27}$ Así, conforme la referida disposición, se libera al titular de la acción de daño ambiental de probar culpa o dolo en el sujeto responsable del hecho dañoso, en el evento que el perjuicio se haya producido por infracción de alguna norma ambiental, sean legales o reglamentaria. Por lo tanto, en caso que el daño ambiental se genere sin infracción del ordenamiento jurídico ambiental, necesariamente se deberá acreditar el elemento subjetivo de la responsabilidad. Al respecto, aunque es posible que se genere un daño ambiental sin infracción de disposiciones ambientales, tal situación sería una manifestación de falencias en el ordenamiento jurídico ambiental por lagunas legales o bajos niveles de protección ambiental. ${ }^{28}$ Así, lo más probable será que el hecho que ocasiona el daño ambiental, coincida con el que es objeto de una infracción a las normas ambientales. Lo anterior tiene una consecuencia no menor, y es que en la práctica, dada la amplitud de la presunción de responsabilidad, se traslada la carga de la prueba del elemento subjetivo -culpa negligencia o dolo- a uno objetivo, que es la vulneración al ordenamiento jurídico. En efecto, lo que quiso hacer el legislador es presumir la responsabilidad por vulneración del derecho ambiental. ${ }^{29}$ Con todo igualmente se debe recordar que es una presunción legal que admite prueba en contrario.

Respecto al tipo de regulación que puede invocarse para aplicar la presunción, el TA ha señalado que "(...) todas las infracciones que dan origen a la presunción lo son respecto de normativa que busca proteger, preservar o conservar el medio ambiente, es decir, tiene una finalidad específica. No se trata de cualquier disposición, sino aquellas cuyo objetivo es evitar que se produzca un daño, no cualquiera, sino ambiental. Por lo tanto, desde el punto de vista del infractor, este no incurre en un incumplimiento a una obligación de cuidado ordinaria, sino que infringe un deber específico que se le exige para un fin determinado, esto es, evitar el daño ambiental". ${ }^{30}$

Por lo tanto, podría estimarse que la presunción de responsabilidad, o más precisamente de culpabilidad, en la práctica opera la mayoría de los casos -por no decir en todos- ya que los daños ambientales generalmente coinciden con el incumplimiento de alguna disposición ambiental, y además siempre las normas del ordenamiento jurídico ambiental tienen por objeto la protección, preservación o conservación del medio ambiente. En este orden de ideas, en atención a la amplitud con la que está establecido este supuesto jurídico, el régimen de responsabilidad se aproxima considerablemente a uno de carácter objetivo. ${ }^{31}$ La presunción de culpa se

${ }^{27}$ En tal sentido FIGUEROA E, ASENJO R., VALDÉS S., PRAUSS S. (2005) "La responsabilidad civil ambiental, el daño al medio ambiente y su valor: Una aproximación legal y económica" en Revista de Derecho Ambiental No 2. Universidad de Chile. P. 70

${ }_{28}$ BERMÚDEZ SOTO J. (2015) "Fundamentos del derecho (...)" [Ob. cit. No 22] P. 396

${ }^{29}$ ídem. P. 398.

${ }^{30}$ Sentencia del Segundo Tribunal Ambiental, causa Rol D-15-2015, considerando No 55

${ }^{31}$ BERMÚDEZ SOTO J. (2015) "Fundamentos del derecho (...) [Ob. cit. №22]. P. 398 
justificaría debido a que a través de la normativa ambiental, la autoridad hace una ponderación ex ante de los riesgos previsibles, estableciendo una regla de conducta. ${ }^{32}$

Además, se debe tener en cuenta que la LGBMA, se establece una causal de exención de responsabilidad ambiental, que opera cuando a pesar de cumplir con la normativa ambiental, de igual forma se produce un daño ambiental, es esos casos solo se puede exigir la indemnización de perjuicios por los daños tradicionales. ${ }^{33}$

Por su parte, la DRMA ${ }^{34}$ y la LRMA reconocen un sistema de responsabilidad híbrido, estableciendo el régimen objetivo pero no de manera absoluta. Solo se exime de probar la culpa negligencia o dolo respecto de aquellas actividades que significan un riesgo de daño ambiental, enumeradas en sus respectivos Anexo III. Respecto de las actividades que no están incorporadas en el referido Anexo, opera sistema subjetivo. Adicionalmente, la LRMA determina el tipo de responsabilidad en atención al tipo de medidas que se tengan que adoptar, es decir, si son preventivas, reparatorias o también de evitación de daños ambientales. En otras palabras, conforme la Ley española, la definición del régimen objetivo o subjetivo de responsabilidad, se basa en función del tipo de actividad que se desarrolle y además del estado en que se encuentre el daño, esto es, si es efectivo, o se encuentra en estado de amenaza inminente, o cuando el daño ha comenzado a manifestarse. En efecto, sobre esta materia la innovación y aporte que presenta la LRMA es que es igualmente aplicable el régimen objetivo de responsabilidad en cuanto la exigencia de la adoptar medidas preventivas y de evitación de daños al medio ambiente, resultando irrelevante si la actividad se encuentra o no establecida en el Anexo III. Sobre este punto, importa destacar que la LRMA además obliga al operador de actividades no contempladas en el Anexo III a adoptar medidas de reparación en caso que hubiese incumplido los deberes relativos a las medidas de prevención y de evitación de daños. El problema es

\footnotetext{
32 BARROS BOURIE E. (2006) "Tratado de responsabilidad extracontractual". Editorial Jurídica de Chile, Santiago de Chile, P. 91.

${ }^{33}$ En tal sentido, el Art. 55 señala que "cuando los responsables de fuentes emisoras sujetas a planes de prevención o descontaminación, o a regulaciones especiales para situaciones de emergencia, según corresponda, acreditaren estar dando íntegro y cabal cumplimiento a las obligaciones establecidas en tales planes o regulaciones sólo cabrá la acción indemnizatoria ordinaria deducida por el personalmente afectado, a menos que el daño provenga de causas no contempladas en el respectivo plan, en cuyo caso se aplicará lo dispuesto en el artículo anterior".

${ }^{34}$ En cuanto a las actividades que aplican el régimen de responsabilidad objetiva, según información aportada por la Comisión Europea, "algunos Estados miembros excluyeron el esparcimiento de lodos de depuración de entre las operaciones de gestión de residuos (Bulgaria, Eslovaquia, Eslovenia, Francia, Letonia, Malta, Portugal, Rumanía y Reino Unido). Algunos Estados miembros incluyeron entre los ámbitos a los que se aplica la responsabilidad objetiva algunas actividades no mencionadas en el anexo III (Bélgica, Dinamarca, Finlandia, Grecia, Hungría, Letonia, Lituania, Países Bajos y Suecia)". Véase "Informe de la Comisión al Consejo, al Parlamento Europeo, al Comité Económico (...)" Ob. cit. P.5
} 
que la Ley no define a qué tipo de deberes se refiere si adoptar las medidas requeridas, entregar la información solicitada, o seguir las instrucciones. Al respecto resulta razonable considerar que solo podrá exigírsele al operador sufragar los costes de las medidas en caso que el incumplimiento sea relevante para la generación o agravamiento del daño, de lo contrario sería desproporcionado. ${ }^{35}$

En definitiva, aunque los sistemas jurídicos tradicionalmente reconocen como regla general el sistema de responsabilidad por culpa, con el paso del tiempo, y desde la época de la revolución industrial, existe una tendencia en reconocer que respecto de determinadas sectores económicos cuyas actividades están asociadas a la generación de un riesgo, debe operar la responsabilidad objetiva. ${ }^{36}$ Así, los sistemas de responsabilidad analizados, aunque no sea de forma expresa, considerando distintas fórmulas regulatorias, incluso a través del desarrollo jurisprudencial, en cierta medida, manifiestan la tendencia a "objetivizar" este tipo de responsabilidad, tanto por la naturaleza de las actividades que generan el daño y también en atención a las particularidades que representa el bien jurídico protegido.

\subsection{Relación de causalidad}

El requisito de la causalidad para configurar la responsabilidad es el que mayor dificultad supone acreditar, y en materia ambiental la complejidad se acentúa por problemas como la pluralidad de causas que puede generar un daño ambiental y también por fenómenos de contaminación difusa. Esta exigencia implica esclarecer si el daño ambiental ha sido ocasionado por una determinada acción u omisión. ${ }^{37}$

Respecto a este requisito de la responsabilidad, importa destacar que el TA ha realizado interpretación extensiva respecto de la presunción de culpabilidad establecida en el Art. 52 LGBMA, en el siguiente sentido: "(...) tal como resolvió este Tribunal en causa Rol D No 14-2014, la presunción del artículo 52 de la Ley 19.300 se extiende también a la causalidad. (...)

Que, es razonable suponer que si se infringe una disposición cuya finalidad es proteger, preservar o conservar el medio ambiente, y se produzcan los efectos que dicha normativa ha querido evitar, se presuma legalmente que el infractor es el

\footnotetext{
${ }^{35}$ VALENCIA MARTÍN G (2010)"Responsabilidad medio ambiental" en Revista General de Derecho Administrativo, $\mathrm{N}^{\circ} 25$, P. 40

${ }^{36}$ GARCÍA AMEZ JAVIER. (2015) "Responsabilidad por daños (...)" Ob. cit. P 236.

${ }^{37}$ Véase GARCÍA AMEZ JAVIER. (2015). "Responsabilidad por daños (...) ob. cit. P. 246248.

Cabe destacar que el autor sugiere seguir una serie de pasos para determinar el vínculo causal: En primer lugar se debe acreditar la causalidad general, lo cual supone dilucidar si la actuación específica puede llegar a causar el daño de manera general, no implica un análisis en concreto, sino que en abstracto, sobre si una determinada acción es apta para ocasionar un daño. El autor destaca que en esta parte cobran importancia las presunciones legales de causalidad. Luego, corresponde probar la causalidad específica, que significa demostrar en concreto si la acción del presunto responsable causó el daño.
} 
causante del daño. Una interpretación en contrario, limitándola solo a la culpa, sin reparar en la finalidad de la norma, no sería coherente con las particularidades que presenta la responsabilidad en el ámbito ambiental, especialmente en cuanto a la dificultad para determinar la causalidad. En este sentido, para que la presunción cubra el nexo causal, se requiere que el daño quede comprendido en el ámbito de protección de la norma infringida" 38

Por lo tanto, de cumplirse los supuestos de la presunción de culpabilidad, y no habiendo sido desvirtuadas por el demandado, según el criterio del TA, ésta también debe extenderse al requisito del nexo causal, siempre y cuando el daño esté considerado en la esfera de protección de la norma que se invocó para configurar la presunción. Esta lógica se basa en que de la vulneración de una normativa que justamente busca evitar la ocurrencia de daños significativos, y por lo tanto es razonable considerar que su infracción sea el hecho que causa el perjuicio. Además, este criterio responde a las particularidades del daño ambiental. En efecto, cumplidos los supuestos para que opere la presunción, para configurar la responsabilidad, restaría acreditar la existencia del daño ambiental significativo.

La LRMA, por su parte, también establece en su Art. 3.1 inc. 2 un presunción de causalidad, según la cual, en caso que el legitimado activo acredite que la actividad de dicho Anexo es apta para causar el daño ambiental o amenaza inminente de tal, se entiende que aquella es la causante del daño. ${ }^{39}$ Por tanto, con la presunción legal de causalidad, se pretende instalar al legitimado activo en una mejor posición para exigir la responsabilidad. No obstante, aunque resulte difícil, el operador y presunto responsable puede desvirtuar la presunción. En este sentido, un sector de la doctrina ha señalado que la referida disposición legal presenta el inconveniente de no considerar una previsión sobre cómo el presunto responsable del daño puede desvirtuarla, pues solo dispone que la presunción cede ante prueba en contrario, y no dice si ésta puede consistir en señalar a otro posible causante del daño, o que el presunto causante del daño acredite que no llevó a cabo una actividad apropiada para causarlo o a la prueba de que efectivamente no lo causó. ${ }^{40}$

Además, tanto la DRMA como la LRMA, contemplan una disposición con la que se pretende resolver el problemas de los daños difusos, [Art. 4.5 y Art. 3.3 respectivamente] al señalar que el sistema de responsabilidad será aplicable a la contaminación de carácter difuso, cuando sea posible establecer un vínculo causal

\footnotetext{
${ }^{38}$ Sentencia, causa Rol D-15-2015, considerandos № 55 y 56 del Segundo Tribunal Ambiental. El mismo razonamiento tuvo el mismo Tribunal en causas anteriores: causa Rol D- 6-2013, considerandos $\mathrm{N}^{\mathrm{o}} 58$.

39 Art. 3.1 inc. 2 LRMA: "se presumirá, salvo prueba en contrario, que una actividad económica o profesional de las enumeradas en el anexo III ha causado el daño o la amenaza inminente de que dicho daño se produzca cuando, atendiendo a su naturaleza intrínseca o a la forma en que se ha desarrollado, sea apropiada para causarlo".

40 XIOL RÍOS J.A. "Sentencia de 2 de noviembre de 2007 (RJ 2008,13)", en Cuadernos Civitas de Jurisprudencia Civil No 88. Thomson Reuters, P.1135.
} 
entre los daños y las actividades de operadores concretos. Sin embargo, la solución que ofrecen ambos sistemas es solo aparente y no resulta acertada ya que como se recordará los daños difusos son aquellos respecto de los cuales no es posible determinar con suficiente certeza la causa que los origina, esa es su característica principal y la razón de su complejidad.

\subsection{Legitimación activa}

En primer término, en virtud del Art. 54 de la LGBMA, son titulares de la acción de reparación de daño ambiental son los siguientes las personas naturales o jurídicas que puedan verse afectados por el daño ambiental, la ley no aporta mayor precisión al respecto, por lo que según los términos que utiliza debe entenderse que están legitimadas las personas naturales o jurídicas, sean públicas o privadas. Para que puedan actuar deben acreditar la afectación que les ocasiona el daño ambiental, requisito al que la LRMA tampoco se refiere.

Para probar esta exigencia, se ha planteado la teoría del entorno adyacente, que propone la idea "de un medio ambiente vinculado o relacionado al ser humano, que resulta necesario para que éste desarrolle sus potencialidades. Por tal debe entenderse aquella porción de extensión variable del entorno o medio que se encuentra de forma adyacente al ser humano, la cual no se reduce a su residencia ni lugar en que desarrolla sus actividades, no solo es su entorno inmediato necesario para la vida (...) es el espacio que él necesita para poder desplegar sus capacidades (...)". ${ }^{41}$

En este sentido, importa destacar que el TA ha acogido la teoría del entorno adyacente y ha reconocido que las organizaciones no gubernamentales [ONG] dedicadas a la protección y conservación del medio ambiente pueden tener legitimación activa. Asimismo, ha complementado la teoría y planteando que para acreditar la legitimación se deben cumplir con ciertos requisitos o consideraciones que se evaluarán caso a caso, "en función del objeto social explicitado en sus estatutos". ${ }^{42}$

La LGBMA además reconoce como legitimados activos de carácter amplio al Estado, representado por el Consejo de Defensa del Estado y a las Municipalidades, que pueden actuar de forma directa o a requerimiento de cualquier persona [Art.54]. Además, reconoce la posibilidad de intervenir en el juicio por daño ambiental como terceros coadyuvantes. Así, en caso que la demanda haya sido interpuesta por alguno de los legitimados, los restantes no podrán hacerlo, y solo podrán intervenir como terceros. Al respecto, se presume que las municipalidades y el Estado tienen interés actual en los resultados del juicio, para los efectos del artículo 23 del Código de

\footnotetext{
${ }^{41}$ Véase BERMÚDEZ SOTO J. (2015) Ob. cit. P. 123.

${ }^{42}$ Sentencia causa D-02-2013, Considerandos 15 y ss. del Segundo Tribunal Ambiental. Este criterio se ha confirmado posteriormente por el mismo tribunal en sentencia causa D-28-2016, Considerandos $\mathrm{N}^{\mathrm{o}} 6$ y ss.
} 
Procedimiento Civil, y por tanto siempre pueden intervenir en el juicio en calidad de terceros coadyuvantes.

Por otra parte, conforme la regulación comunitaria, el procedimiento de responsabilidad ambiental podrá iniciarse de oficio por la autoridad competente que designe cada estado miembro o a solicitud de las personas legitimadas que se establecen en la Directiva en su Art. 12, que podrán presentar una solicitud de acción, requiriendo a dicha autoridad que actúe conforme a la DRMA, y además, presentar a la misma autoridad observaciones respecto a los casos de daño ambiental o de amenaza inminente del tal daño.

En el caso de la legislación española, la LRMA regula un régimen administrativo de responsabilidad ambiental, en la medida en la que consagra todo un conjunto de potestades administrativas mediante las cuales la Administración pública debe garantizar el cumplimiento y la aplicación del régimen de responsabilidad que incorpora. En tal sentido, el desarrollo legislativo y la ejecución de la LRMA, con carácter general, le corresponde a las comunidades autónomas en cuyo territorio se localicen los daños causados o la amenaza inminente de que los mismos se produzcan. En esta línea, conforme la LRMA, el procedimiento puede iniciarse de oficio por la Administración o a solicitud de parte. Esta última forma puede producirse bien a instancia de algún interesado que establece la Ley o también del operador causante del daño ambiental o de la amenaza que se produzca. La posibilidad que se inicie el procedimiento a solicitud del operador es una innovación de la LRMA, que no se establece en la DRMA [Art 41].

Respecto a los interesados facultados para solicitar el inicio del procedimiento de responsabilidad, interesa destacar que la DRMA establece que las ONG que trabajan en la protección del medio ambiente son legitimadas activas para instar medidas preventivas y reparatorias por considerar que tienen interés suficiente y que tienen derechos que pueden verse vulnerados. En esta línea, la LRMA reconoce la legitimación a las ONG, en la medida que cumpla los siguientes requisitos: ${ }^{43}$

a. Que en sus estatutos contemplen como finalidad la protección del medio ambiente en general o la de alguno de sus elementos en particular.

b. Que se hubieran constituido legalmente al menos dos años antes del ejercicio de la acción y que vengan ejerciendo de modo activo las actividades necesarias para alcanzar los fines previstos en sus estatutos.

c. Que realicen su actividad en un ámbito territorial que resulta afectado por el daño medioambiental o la amenaza de daño [Art 42 b].

En suma, cabe destacar que según la LGBMA la legitimación activa del sistema de responsabilidad por daño ambiental de carácter amplio, en cuanto considera actores

\footnotetext{
${ }^{43}$ Los requisitos son los mismos que establecida en el Art. 23 de la Ley 27/2006, de 18 de julio, por la que se regulan los derechos de acceso a la información, de participación pública y de acceso a la justicia en materia de medio ambiente, que se exigen para reconocer la legitimación activa para interponer la acción popular en asuntos medioambientales,
} 
de distinta naturaleza, pero determinada ya que no considera una acción popular. ${ }^{44}$ En este sentido, a pesar que se ha asentado el criterio jurisprudencial que establece una alcance amplio del concepto de legitimación activa, se considera que para garantizar el derecho de acceso a la justicia ambiental y aportar mayor seguridad jurídica, es importante que la LGBMA reconozca expresamente la legitimación activa de las $\mathrm{ONG}$, en atención al rol que cumplen y a la forma en que pueden contribuir en darle operatividad al régimen de responsabilidad, ya que su efectividad depende de la interposición de la acción de reparación ambiental. Con todo, para el reconocimiento de estas instituciones como legitimados se deben exigir ciertos requisitos para efectos de evitar abusos o falta de seriedad en el ejercicio de la acción. Al respecto, los requerimientos que plantea la LRMA podrían evaluarse para efectos de evitar abusos y falta de seriedad en la interposición de la acción de reparación.

\subsection{Prescripción}

La temporalidad del daño ambiental es una problema frecuente en este tipo de daños ya que en muchos casos resulta difícil determinar cuándo se generó el daño, debido a que los efectos no son siempre evidentes o pueden tardar tiempo en manifestarse.

El plazo que establece la LGBMA es de cinco años [Art. 63 LGBMA] -la acción de responsabilidad extracontractual es de cuatro años conforme el Art. 2332 del Código Civil-. Por su parte, tanto la DRMA como la LRMA, contemplan un plazo considerablemente mayor de treinta años para hacer efectiva la responsabilidad ambiental. [Art. 17 y Art. 4, respectivamente]. ${ }^{45}$

Ahora bien, además de la extensión del plazo, otro aspecto decisivo en esta materia es definir el momento desde el cual se debe computar el plazo. Al respecto, el sistema chileno dispone que debe ser desde la manifestación evidente del daño [Art. 63 LGBMA]. Por su parte, la DRMA no hacen precisiones sobre ese punto, mientras que la LRMA dispone que el plazo se computará desde el día en el que haya terminado por completo o se haya producido por última vez la emisión, el suceso o el incidente causante del daño [Art.4]. De lo anterior se desprende un punto relevante a tener en cuenta, y es que se debe distinguir entre el daño y la actividad que lo ocasiona, porque la prescripción se refiere a lo primero, es decir, no se debe considerar la causa del daño, sino que a sus efectos. ${ }^{46}$ Con todo, en la doctrina y jurisprudencia existe consenso en esta materia, y se considera que el cómputo del plazo de prescripción de los daños continuos solo comienza a correr desde el

\footnotetext{
${ }^{44}$ BERMÚDEZ SOTO J. (2015) "Fundamentos del derecho (...)" Ob. cit. P. 414

${ }^{45}$ Art. 4 LRMA: "no será de aplicación a los daños medioambientales si han transcurrido más de treinta años desde que tuvo lugar la emisión, el suceso o el incidente que los causó $(\ldots)^{\prime \prime}$.

${ }^{4}$ RUDA GÓNZÁLEZ A. (2010)."Responsabilidad extracontractual.Daños medioambientales. Prescripción. Daños continuados. Dies a quo. Sentencia de 29 de junio de 2009 (RJ 2009, 4761) 2199", en Cuadernos Civitas de Jurisprudencia Civil No 83. Thomson Reuters, P.881.
} 
momento en que tiene lugar la producción del resultado dañoso definitivo. ${ }^{47}$ En otras palabras, se cuenta desde constatación última y total del daño.

\subsection{Reparación del daño ambiental}

Al hacerse efectiva la reparación del daño ambiental, se materializa el principio de quien contamina paga, en el sentido que el responsable debe internalizar y asumir los costes asociados a la reparación. ${ }^{48}$ La obligación de reparar el daño en el contexto de la responsabilidad ambiental tiene características especiales que lo diferencian del sistema de responsabilidad extracontractual.

Por una parte, la reparación mediante la indemnización de perjuicios no se presenta como una alternativa aplicable en esta materia ya que la entrega de una cantidad de dinero al afectado no es una opción funcional al objetivo principal de todo sistema de responsabilidad ambiental que es reparar materialmente el daño generado al medio ambiente.

En el ámbito comunitario y en España, la procedencia de la indemnización de perjuicios como alternativa reparatoria no es materia de discusión. De hecho, el preámbulo de la LRMA expresamente señala que la indemnización de perjuicios es una forma inadecuada para reparar este tipo de daños: "Al poner el énfasis en la restauración total de los recursos naturales y de los servicios que prestan, se prima el valor medioambiental, el cual no se entiende satisfecho con una mera indemnización dineraria". En este sentido, VALENCIA destaca que ni siquiera se debe considerar para los daños irreparables. ${ }^{49}$ Sin embargo, en Chile existen voces que consideran que, en ciertos casos, cuando no es posible la reparación material del daño de las formas que establece LGBMA y existe un daño irreparable, la indemnización de perjuicios opera como una reparación por equivalencia. ${ }^{50}$

Ahora bien, esta alternativa sin duda procede para reparar los perjuicios personales o patrimoniales derivados del daño ambiental. En este sentido, una nota distintiva de este tipo de regímenes consiste en reconocer que producto de un daño ambiental, pueden ocasionarse dos tipos de perjuicios: El daño ambiental propiamente tal o daño ecológico puro ${ }^{51}$ y los daños personales o patrimoniales ocasionados producto de aquél, también denominados daños tradicionales. ${ }^{52}$ Los tres sistemas que se analizan

47 Ídem.

${ }^{48}$ RUDA GONZÁLEZ A. (2008) "El daño ecológico puro.(...)" Ob. cit. P. 464.

${ }^{49}$ En este sentido VALENCIA MARTÍN G (2010) "Responsabilidad medio ambiental" en Revista General de Derecho Administrativo, No 25, P. 11

${ }^{50}$ Véase VIDAL A. (2007) "Las acciones civiles derivadas del daño ambiental en la Ley 19.300". Revista de Derecho de la Pontificia Universidad Católica de Valparaíso XXIX. Valparaíso, Chile P. 136-138

${ }^{51}$ RUDA GONZÁLEZ A. (2008) "El daño ecológico puro. .(...)" Ob. cit. P. 34

52 VALENCIA MARTÍN G (2010) "Responsabilidad medio ambiental" en Revista General de Derecho Administrativo $\mathrm{N}^{\mathrm{o}} 25$, P.6. En este sentido, otros autores también se refieren a la 
reconocen esta diferencia en su regulación [el sistema chileno en el Art. 3 LGBMA y en el Art. 46 LTA, la DRMA en su considerando 15, y la LRMA en su Art. 5].

Por otra parte, la tradicional forma de reparación in natura o restitutio in integrum del régimen extracontractual, siendo entendida tradicionalmente como aquella reparación en que se repone la cosa al estado anterior de producirse el daño, en materia de responsabilidad ambiental, su funcionalidad admite a lo menos consideraciones especiales. En este ámbito, en la mayoría de los casos no se puede recomponer el componente ambiental afectado al estado exacto en que se encontraba antes de producirse el daño. Así por ejemplo, la quema de un bosque con especies naturales protegidas obviamente es imposible que pueda volver al estado anterior del daño. Por lo tanto, la reparación in natura en sentido estricto, resulta poco realista. En este sentido, la finalidad de una acción reparatoria es que en la medida de lo posible, desaparezcan las huellas del daño ambiental. ${ }^{53}$ Este criterio responde a la complejidad del medio ambiente como objeto de reparación, y también al hecho que solo se puede imputar responsabilidad y exigir recomponer el daño ambiental en la medida que sea significativo. En efecto, entre mayor sea la intensidad o gravedad del daño ambiental, más difícil será conseguir ese tipo de reparación. ${ }^{54}$

$\mathrm{Al}$ respecto, autores como BERMÚDEZ son de una posición estricta y sostienen que este tipo de reparación no es aplicable en esta materia. ${ }^{55}$ Mientras que otros como RUDA $^{56}$ y VALENCIA, ${ }^{57}$ tienen una postura más moderada debido a que reconocen que la reparación in natura en el ámbito de la responsabilidad ambiental opera pero con matices. Con todo, ambas perspectivas llegan a la misma conclusión: Exigir que el medio ambiente o su componente por la ejecución de la medida de reparación vuelva al estado exacto es un objetivo prácticamente inalcanzable. En efecto, a lo que se puede aspirar a través de una medida reparatoria es a recuperarlo a un estado aproximado o similar, pero nunca a uno idéntico. En todo caso, los sistemas de responsabilidad que se analizan integran este matiz y reconocen una técnica reparatoria especial.

distinción entre daños ambientales propiamente tales y los daños tradicionales, como BETANCOR RODRÍGUEZ A. (2014) "Derecho Ambiental". La Ley Grupo Wolters Kluwer. Madrid. P.1550.

${ }^{53}$ RUDA GONZÁLEZ A. (2008) "El daño ecológico puro. La Responsabilidad civil por el deterioro del Medio Ambiente, con especial atención a la Ley 26/2007, de 23 de octubre, de Responsabilidad Medioambiental." Thomson Aranzadi. Navarra. P. 464.

${ }_{55}^{54}$ BERMÚdDEZ SOTO J. (2015) "Fundamentos del derecho (...)" Ob. cit. P.408

${ }^{55}$ El autor al analizar la fórmula reparatoria de la LGBMA señala que "la reparación en una calidad similar no debe ser entendida como una reparación in natura, que exige la identidad con el objeto de reparación, sino que una reparación que restablezca los servicios ambientales que prestaba el medio o elemento ambiental dañado"

Ob. cit. P. 409.

${ }^{56}$ RUDA GONZÁLEZ A. (2008) "El daño ecológico puro. (...) Ob. cit. P. 463 - 466.

${ }^{57}$ VALENCIA MARTÍN G (2010) "Responsabilidad medio ambiental" en Revista General de Derecho Administrativo. $\mathrm{N}^{\circ} 25$ P. 11-12. 
Las formas de reparar el daño ambiental significativo que reconoce el sistema de responsabilidad chileno, derivan del concepto de reparación que establece la LGBMA, "la acción de reponer el medio ambiente o uno o más de sus componentes a una calidad similar a la que tenían con anterioridad al daño causado o, en caso de no ser ello posible, restablecer sus propiedades básicas" [Art. 2 s)]. Según esto, la medidas deben estar orientadas a reparar el medio ambiente o uno de sus componentes a una calidad similar $^{58}$ y, si no es posible, las medidas deben restablecer sus propiedades básicas. Sin embargo, el sistema chileno de responsabilidad no establece criterios para entender cuál es la forma de reparar cuando ni siquiera sea posible restablecer las propiedades básicas del medio ambiente o uno o más de sus componentes y se trata de un daño ambiental irreparable. Es en este escenario, en el que autores como VIDAL considera la procedencia de la reparación por equivalencia. ${ }^{59}$ Por su parte, BARROS sostiene que la eficacia de la acción de reparación está condicionada a la posibilidad de reparar el medio ambiente dañado, y excluye la indemnización de perjuicios para el daño ambiental puro. ${ }^{60}$

En esta materia, BERMÚDEZ presenta una solución a la que adherimos por estar alineada con los fines que plantea la LGBMA. El autor propone incorporar la "compensación ambiental" como forma de restablecer las propiedades del medio ambiente o elemento ambiental dañado. Para tales efectos, hace referencia al concepto de medida de compensación que establece el Reglamento del Sistema de Evaluación de Impacto Ambiental [RSEIA] ${ }^{61}$, que las define como aquellas que "tienen por finalidad producir o generar un efecto positivo alternativo y equivalente a un efecto adverso identificado, que no sea posible mitigar o reparar. Dichas medidas incluirán, entre otras, la sustitución de los recursos naturales o elementos del medio ambiente afectados por otros de similares características, clase, naturaleza, calidad y función" [Art. 100]. A mayor abundamiento, el referido autor precisa que si bien la LGBMA no aporta un concepto, y que solo se reconoce la compensación en el contexto del sistema de evaluación de impacto ambiental y por efectos de la contaminación lícita o permitida ocasionada, por un proyecto o actividad de desarrollo, esta noción no debe entenderse ajena de la responsabilidad ambiental. En efecto, indica que respecto de un daño ambiental que no es posible de reparar a una calidad similar, el TA puede hacer una interpretación progresiva del concepto "propiedades básicas" incorporando la posibilidad de compensación en un lugar distinto a aquél en que se generó el daño ambiental. Por lo tanto, aunque el restablecimiento de las propiedades básicas no sea

\footnotetext{
${ }^{58}$ En la discusión de la LGBMA, con criterio de realidad, se hace presente que al reparar el medio ambiente dañado solo se puede hacerlo volver a una calidad "similar" y no idéntica Véase CONGRESO NACIONAL (1994) "Historia de la Ley No 19.300" P. 586.

${ }^{59}$ Véase VIDAL A. (2007) "Las acciones civiles (...)" P. 136-138

${ }^{60}$ BARROS BOURIE E. (2006) "Tratado de responsabilidad extracontractual". Editorial Jurídica de Chile, Santiago de Chile, P. 811-812.

${ }^{61}$ D.S. No 40/2012 del Ministerio del Medio Ambiente.
} 
posible en el lugar exacto en que se produjo el daño ambiental, siempre será posible en un lugar diferente, pero siempre que se cumpla con la finalidad de reparación ambiental. Sin embargo, advierte que esta solución presenta una dificultad práctica, y es que en un proceso de reparación por daño ambiental, la litis está definida por la demanda. En consecuencia, sólo podría operar la compensación como restablecimiento de las propiedades básicas en un lugar diferente a aquél en que se ocasionó el daño, si la demanda así lo establece, y es considerada como suficiente por el TA, o también en caso que el mismo Tribunal lograse generar un acuerdo en ese sentido. $^{62}$

Por otra parte, y relacionado a lo anterior, cabe recordar que en la demanda sólo se podrá pedir declaración de haberse producido el daño ambiental por culpa o dolo del demandado y la condena de éste a repararlo materialmente de conformidad a la LGBMA [Art. 33 inc. 1]. En efecto, el TA cuando acoge una acción de reparación por daño ambiental, junto con declarar que el demandado fue el responsable de ocasionarlo, lo condena a repararlo mediante la adopción de una serie de medidas específicas que indica. Sin embargo, al ordenar la ejecución de las medidas reparatorias, en la práctica establece acciones concretas para reparar el daño ambiental en atención al caso específico y en general, no especifica a qué alternativa establecida en la LGBMA corresponden -calidad similar, restableciendo las propiedades básicas-, o si aplica otra forma mediante una interpretación extensiva del ordenamiento jurídico ambiental. Por lo tanto, el alcance y contenido de cada una de las medidas reparatorias puede ser muy variado.

Por su parte, la DRMA y la LRMA, en sus respectivos Anexos II establecen tipologías de medidas para reparar el daño ambiental, y los criterios para elegir la más adecuadas. Adicionalmente, el RLRMA aporta de forma más detallada un marco metodológico y elementos adicionales, que delimitan el marco de elección de las medidas de reparación.

En definitiva, con base a la citada regulación, los factores que se consideran para la definición de medidas se traducen en los siguientes:

\section{a) Tipo de recurso afectado}

Como se ha señalado, los referidos sistemas de responsabilidad se centran en bienes ambientales determinados. En relación aquellos, se distinguen dos categorías, cada cual considera fórmulas reparatorias diferentes. El primer grupo corresponde a la reparación de daños a las aguas o a las especies, hábitats naturales protegidos y a ribera del mar y de las rías - estos últimos solo los incorpora la LRMA-; y el segundo, está asociado a la reparación de daños al suelo.

b) La finalidad que se debe cumplir con la medida específica

Respecto a la primera categoría de elementos naturales objeto de protección, se establecen tres formas reparatorias: (i) La reparación primaria, que tienen por

${ }^{62}$ BERMÚdEZ SOTO J. (2015) "Fundamentos del derecho (...)" Ob. cit. P.410- 411 
finalidad restituir o aproximar los recursos naturales y/o servicios dañados a su estado básico, en el lugar en que se produjo el daño ambiental; (ii) la reparación complementaria opera cuando los elementos naturales o sus servicios no se restituyen a su estado básico, y debe estar orientada a proporcionar un nivel de recursos naturales y/o servicios similar al que se habría proporcionado si se hubiera restituido a su estado básico, incluso la medida procede en un lugar alternativo; y (iii) la reparación compensatoria, que tiene por finalidad compensar las pérdidas provisionales que tengan los elementos naturales o sus servicios, hasta que las medidas de reparación primarias o complementarias hayan tenido efecto.

En relación a la reparación del suelo, la medida debe estar orientada a lo menos, a evitar que la contaminación del suelo suponga un riesgo significativo para la salud humana y además, la LRMA agrega que deben impedir que el daño ambiental represente un riesgo significativo para el medio ambiente.

\section{c) Criterios basados en las mejores técnicas disponibles}

En general, al evaluar las opciones de medidas reparatorias se considera que debe atenderse, a lo menos, al efecto que generan en la salud y seguridad pública; al coste asociado a su implementación; probabilidad de éxito; su utilidad para prevenir daños futuros y evitar daños colaterales; la medida en que cada opción abordará intereses sociales, económicos, culturales y otros factores pertinentes; el periodo de tiempo para que la medida sea efectiva; el nivel en que la alternativa logra reparar el daño ambiental y vinculación geográfica con el paraje dañado.

En cuanto a la fórmula de reparación de la DRMA y la LRMA importa destacar el rol que le confieren a la autoridad competente para garantizar los objetivos que plantean, tanto por la facultad que se le otorga para requerir información, dar instrucciones y exigir a los operadores que ejecuten las medias correspondientes, y también, por la posibilidad que tiene para adoptar de forma directa medidas reparatorias y preventivas de daño ambiental. En este sentido, también cabe resaltar que la LRMA regula circunstancias especiales asociadas a los operadores para hacer efectivas la adopción de las correspondientes medidas, tales como la responsabilidad solidaria, responsabilidad subsidiaria y responsabilidad de los grupos de sociedades.

En suma, y a modo de recapitulación, la DRMA y la LRMA contemplan tres modalidades de reparación -primaria complementaria y compensatoria-, y respecto de cada una se detallan los lineamientos para aplicar la mas adecuada. Además, le atribuyen a la autoridad competente un rol central para garantizar su debido cumplimiento. Sumado a lo anterior, la LRMA particularmente, dispone de distintas figuras jurídicas que buscan garantizar y dar cobertura efectiva a las medidas de reparación del daño ambiental. Mientras que la LGBMA, establece un catálogo restringido de formas de reparar el medio ambiente, que no presenta alternativas que respondan a todos los efectos posibles que puede generar el daño ambiental, esto es cuando ni siquiera se puede restablecer sus propiedades básicas del medio ambiente o sus componentes, o cuando el daño ambiental es irreversible. Frente a ese tipo de daños, debe optarse por la compensación ambiental como forma de restablecer las 
propiedades del medio ambiente ya que de esta forma, se le da primacía al valor ambiental y se hace efectivo los principios que inspiran la LGBMA. En este orden de ideas, considerando que esta forma de reparación implica una "valoración ecosistémica" del daño ambiental, de la regulación comunitaria y española deberían considerarse los criterios de equivalencia -recurso/recurso, servicio/servicio-, considerados en los Anexos II respectivos y que son desarrollados con mayor profundidad en el RLRMA.

Además, en cuanto al alcance de la obligación de reparar el daño ambiental, cabe señalar que no solo implica reponer el medio ambiente o alguno de sus componentes dañados, sino también eliminar la fuente que generó el perjuicio para que no se siga produciendo. Asimismo, la LGBMA al establecer que el medio ambiente o uno de sus componentes se entiende reparado al reponerlo a una calidad similar, no debe entenderse como un criterio reparatorio de mínimos, en el que baste o resulte suficiente lograr ese estado del elemento natural, sino que supone reconocer un criterio de realidad en la forma en que se puede subsanar este tipo de daños.

\section{Conclusiones}

Primera conclusión: En general los elementos que estructuran un régimen de responsabilidad por daño ambiental que hace diferenciarlos respecto del sistemas tradicional de responsabilidad extracontractual consisten en reconocer la diferencia que existe entre los daños ambientales y los daños tradicionales generados a causa del daño ambiental, señalando que estos últimos deben exigirse en sede civil; en establecer plazos más extensos y particularidades respecto al cómputo de la prescripción; en considerar una legitimación activa de carácter amplio; presunciones para favorecer la prueba del requisito de culpabilidad y causalidad un procedimiento. Con todo, particularmente, las diferencias dependerán también de la naturaleza jurídica del procedimiento para determinar la responsabilidad ambiental, vale decir, si es judicial o de carácter administrativo.

El régimen que establece la DRMA y la LRMA, van mucho más allá, y abren una nueva perspectiva en el tratamiento de los daños ambientales y en la forma en que se debe responder por ellos. El valor y novedad que presentan estos sistemas, principalmente radica en la doble finalidad que plantean ya que no solo se ocupan de los daños ya producidos, sino que también de la amenaza inminente de los mismos. Es aquí donde se evidencia también la separación de la lógica común de los sistemas tradicionales de responsabilidad.

En este sentido, también cabe destacar el avance que la LRMA supone respecto de la DRMA. Fundamentalmente por la ampliación del régimen objetivo el cual se extiende la obligación del operador de actividades comprendidas o no en el Anexo III de adoptar medidas preventivas y de evitación de daños.

Segunda conclusión: El régimen de responsabilidad ambiental de la LGBMA contempla conceptos jurídicos indeterminados, y vacíos normativos. Para salvar las deficiencias normativas el desarrollo jurisprudencial es fundamental. En este sentido, 
se han consolidado criterios jurisprudenciales que determinan la significancia del daño ambiental, también respecto de la definición del alcance de la presunción de culpabilidad del Art. 52. LGMA que la hacen extensiva su aplicación al requisito de causalidad. Asimismo, se han asentado criterios para definir la afectación por el daño ambiental, como requisito para reconocer legitimación activa.

Relacionado a lo anterior, de la DRMA y la LRMA, algunos elementos que dan cuenta de la particularidad del daño ambiental y que podrían considerarse son los parámetros y metodología para determinar la entidad del daño; el establecimiento de alternativas de medidas de reparación y los criterios para definir la más adecuada; la amplitud del plazo de prescripción para hacer efectiva la responsabilidad ambiental. También importa destacar el reconocimiento de las ONG como legitimados activos y los requisitos para definirlos como tales.

\section{Bibliografía}

Barros Bourie E. (2006) "Tratado de responsabilidad extracontractual". Editorial Jurídica de Chile, Santiago de Chile.

Bermúdez Soto J. (2015) "Fundamentos del derecho ambiental". Ediciones Universidad de Valparaíso. Pontificia Universidad Católica de Valparaíso. $2^{\circ}$ Edición.

Betancor Rodríguez A. (2014) "Derecho Ambiental". La Ley Grupo Wolters Kluwer. Madrid.

Dopazo Fraguío, P. (2005) "El sistema jurídico de responsabilidad medioambiental: Análisis de riesgos y compliance legal”, en Revista Aranzadi de Derecho Ambiental, número en Homenaje al Profesor D. Ramón Martín Mateo, 2015. Editorial Thomson- Aranzadi.

Esteve Pardo José (2008). "Ley de responsabilidad medioambiental. Comentario sistemático". Marcial Pons. Madrid.

Figueroa E, Asenjo R., Valdés S., Prauss S. (2005) "La responsabilidad civil ambiental, el daño al medio ambiente y su valor: Una aproximación legal y económica" en Revista de Derecho Ambiental No 2. Universidad de Chile. P. 69-95.

García Amez Javier. (2015) "Responsabilidad por daños al medio ambiente" Thomson Reuters Aranzadi. Pamplona.

García Burgués J. (2008) "Derecho europeo medioambiental. La protección del medio ambiente en la Unión Europea", en Derecho europeo medioambiental: La protección del medio ambiente en la Unión Europea. Aspectos críticos. Consejo General del Poder Judicial. Estudios de Derecho Judicial No 134. P. 11-43.

Lozano Cutanda B. (2017) "Derecho ambiental administrativo", $10^{\circ}$ Edición, Madrid.

Orteu Berrocal E. (2008) "Ámbito de aplicación de la Ley (arts. 3 a 6 y definiciones relacionadas)", en "Comentarios a la Ley de Responsabilidad Medioambiental (Ley 26/2007, de 23 de octubre)". Thomson-Civitas, Cizur Menor. Navarra. P. 165 y ss.

Ruda Gónzález A. (2010)."Responsabilidad extracontractual. Daños medioambientales. Prescripción. Daños continuados. Dies a quo. Sentencia de 29 de junio de 2009 (RJ 2009, 4761) 2199", en Cuadernos Civitas de Jurisprudencia Civil No 83. Thomson Reuters, P. 873- 883 . 
Ruda González A. (2008) "El daño ecológico puro. La Responsabilidad civil por el deterioro del Medio Ambiente, con especial atención a la Ley 26/2007, de 23 de octubre, de Responsabilidad Medioambiental." Thomson Aranzadi. Navarra.

Soro Mateo, B. (2009) "Consideraciones críticas sobre el ámbito de aplicación de la Ley de responsabilidad ambiental”, en Revista Aragonesa de Administración Pública, No. 35, P. 185-221.

VAlencia Martín G (2010) "Responsabilidad medio ambiental", en Revista General de Derecho Administrativo No 25. P. 1 - 62.

Vidal A. (2007) "Las acciones civiles derivadas del daño ambiental en la Ley 19.300". Revista de Derecho de la Pontificia Universidad Católica de Valparaíso XXIX. Valparaíso, Chile. P. 119-140.

Xiol Ríos J.A. "Sentencia de 2 de noviembre de 2007 (RJ 2008,13)", en Cuadernos Civitas de Jurisprudencia Civil No 88. Thomson Reuters, P. 1119 -1149. 